\title{
Sistema de classificação facetada e tesauros: instrumentos para organização do conhecimento*
}

\author{
Ana Maria Delazari Tristão \\ Doutoranda do Programa de Pós-graduação em Engenharia Civil, \\ da Universidade Federal de Santa Catarina \\ E-mail: amdt@floripa.com.br \\ Gleisy Regina Bóries Fachin \\ Mestre em engenharia de produção e professora do Departamento \\ de Ciência da Informação, da Universidade Federal de Santa \\ Catarina \\ E-mail: gleisy@cin.ufsc.br

\section{Orestes Estevam Alarcon} \\ Doutor em engenharia mecânica e professor do Departamento \\ de Engenharia Mecânica, da Universidade Federal de Santa \\ Catarina \\ E-mail: orestes@materiais.ufsc.br
}

\section{Resumo}

O artigo tem o objetivo de aprofundar questões teóricas e conceituais que fundamentam a concepção de sistema de classificação facetada e o tesauro. Apresenta aspectos teóricos referentes aos meios utilizados para organização e recuperação da informação. Os sistemas para organização do conhecimento incluem uma variedade de esquemas para organizar, gerenciar e recuperar a informação, existindo vários tipos de sistemas. Dentre eles, podemos citar sistemas de classificação, tesauro, cabeçalhos de assuntos, ontologia, glossários e dicionários. Descrevem-se princípios, natureza e tipos de sistemas de classificação, com especial ênfase aos sistemas de classificação facetada e o tesauro.

Palavras-chave

Sistema de classificação; Classificação facetada; Tesauro; Organização do conhecimento.

\section{Faceted classification system and thesaurus: technical instruments for knowledge organization}

\begin{abstract}
The objective of this article is to contribute to and thoroughly analyze theoretical and conceptual questions which are the base for a conception of faceted classification systems and thesaurus. Theoretical aspects about the means utilized in information organization and retrieval are presented. The systems of knowledge organization include different schemes for organizing, managing and retrieving information. There are different types of systems, for instance, classification system, thesaurus, subject heading, ontology, glossaries and dictionaries. Principles, nature and types of classification systems are described, with special emphasis on the systems of faceted classification and thesaurus.
\end{abstract}

Keywords

Classification System; Faceted classification; Thesaurus; Knowledge organization.

Ci. Inf., Brasília, v. 33, n. 2, p. 161-171, maio/ago. 2004

\section{INTRODUÇÃO}

Da sinonímia dos termos organização e conhecimento, retira-se que a síntese mais produtiva, ou mais instigadora, para a construção de uma idéia acerca da organização do conhecimento na sociedade é aquela que abstrai de organização, pelo verbo organizar, os sentidos de ORGANIZAR, que são os seguintes: estabelecer as bases de; arrumar de determinado modo; colocar em certa ordem (Souza, 1998).

Para que se possa abordar teoricamente a organização do conhecimento enquanto área de estudos, inicialmente, há de se diferenciar duas concepções de conhecimento: a) enquanto processo individual, constitui, na concepção de Dahlberg (1995) e uma certeza subjetiva ou objetivamente conclusiva da existência de um fato ou do estado de um caso, não sendo transferível e somente podendo ser adquirido por meio de reflexão; b) enquanto algo sobre o qual existe um certo consenso social. Trabalha-se aqui com o conhecimento registrado e divulgado (Guimarães, 2000 apud Straioto, 2001).

Sistemas para organização do conhecimento incluem a variedade de esquemas que organizam, gerenciam e recuperam a informação. Existem desde os tempos remotos e estão presentes em todos as áreas do conhecimento humano, de modo simples aos mais complexos. Esses sistemas abrangem classificação, tesauro, ontologia, assim os conhecidos glossários e dicionários, específicos a cada área e, em sua maioria, ligados a bibliotecas e outras organizações de gerenciamento da informação visando a organizar, recuperar e disseminar a informação. Dessa maneira, adotam-se como definições dos termos que se seguem, os mais referenciados no literatura:

a) Classificação: conjunto de conceitos organizados sistematicamente de acordo com os critérios ou características escolhidas (ISO TR 14177, 1994).

b) Tesauro: definido como um vocabulário de termos relacionados genérica e semanticamente sobre determinada área de conhecimento (Motta, 1987).

\footnotetext{
* Artigo elaborado a partir da revisão de literatura para a pesquisa de doutorado de Ana Maria Delazari Tristão.
} 
c) Ontologia: especificação formal e explícita de uma conceitualização compartilhada (Gruber, 1993), em que:

- conceitualização se refere a um modelo de fenômeno abstrato no mundo por ter identificado os conceitos relevantes daquele fenômeno;

- explícito significa que o tipo dos conceitos usados e as restrições no seu uso são definidos explicitamente;

- formal se refere ao fato de que a ontologia deveria ser lida pela máquina;

- compartilhado reflete que ontologia deveria capturar conhecimento consensual aceito pelas comunidades.

Assim, os sistemas de classificação e os tesauros são linguagens documentárias, ou seja, são sistemas artificiais de signos normalizados que permitem representação mais fácil e efetiva do conteúdo documental, com o objetivo de recuperar manual ou automaticamente a informação que o usuário solicita. Entende-se que as linguagens documentárias é que farão a comunicação entre a linguagem natural dos usuários e a unidade de informação, elas são utilizadas para representar o conteúdo dos documentos, por isso alguns autores as definem como sistemas simbólicos instituídos, que visam a facilitar a comunicação.

Estudiosos de áreas diversas do conhecimento têm voltado suas atenções e pesquisas para a questão da representação da informação, para a organização do conhecimento, e vêem na classificação a maneira de ordenação desse conhecimento, pensando nas teorias da mesma como parte de uma área de estudos conhecida como organização do conhecimento, também citada como representação do conhecimento. Tanto que a International Society for Knowledge Organization (ISKO) considera que os princípios teóricos da classificação e as pesquisas sobre tesauros podem ser utilizados na organização dos mais diversos sistemas gerais e específicos de organização e representação do conhecimento (Straioto, 2001).

A literatura tem mostrado que a classificação está presente não apenas nos sistemas que visam à recuperação de informação, mas na base de sistemas e atividades que se ocupam da organização do conhecimento em suas diferentes manifestações, como, por exemplo, os sistemas de inteligência artificial e hipertextos, agora tão presentes quanto as tecnologias de ponta, levando os estudiosos da área a pesquisas constantes no desenvolvimento de sistemas. Assim, segundo Gomes (1996), a unidade a ser manipulada nesses sistemas e atividades é o conceito, que é a unidade de conhecimento.
Nesse contexto, destaca-se Guimarães (2000) apud Straioto (2001), quando ressalta a dimensão cíclica da organização do conhecimento como o estudo das propriedades de organização de um conhecimento registrado sob a perspectiva de geração de novo conhecimento que, uma vez registrado, transforma-se em informação, ou seja, conhecimento em ação que, incorporado a outros saberes, gera novo conhecimento. $\mathrm{O}$ conhecimento, quando registrado e divulgado, passa a ser informação, reiniciando sempre um círculo contínuo.

Nesse âmbito, Dobedei (2002) também destaca a dimensão cíclica da organização do conhecimento, ao apresentar o modelo de caráter sistêmico denominado "Ciclo da Informação", ou modelo de "Transferência da Informação”, que reduz a realidade da representação do conhecimento a seis etapas: produção, registro, aquisição, organização, disseminação e assimilação. Essas etapas procuram simplificar os processos criados pela produção, acumulação e uso de conhecimento e os produtos gerados em suas várias formas representacionais, sejam fontes primárias, secundárias ou terciárias.

Destaca, ainda, a autora, que esse modelo, até o momento, é o mais adequado para representar o processo de transferência da informação, bem como o papel exercido pelo segmento social envolvido nessa transferência e a estrutura das instituições de preservação da memória social. Incorpora no modelo o conceito "memória documentária”, dividindo o universo do conhecimento em dois subconjuntos: informação e documento, conforme se pode observar na figura 1.

\section{FIGURA 1 \\ Ciclo da Informação}

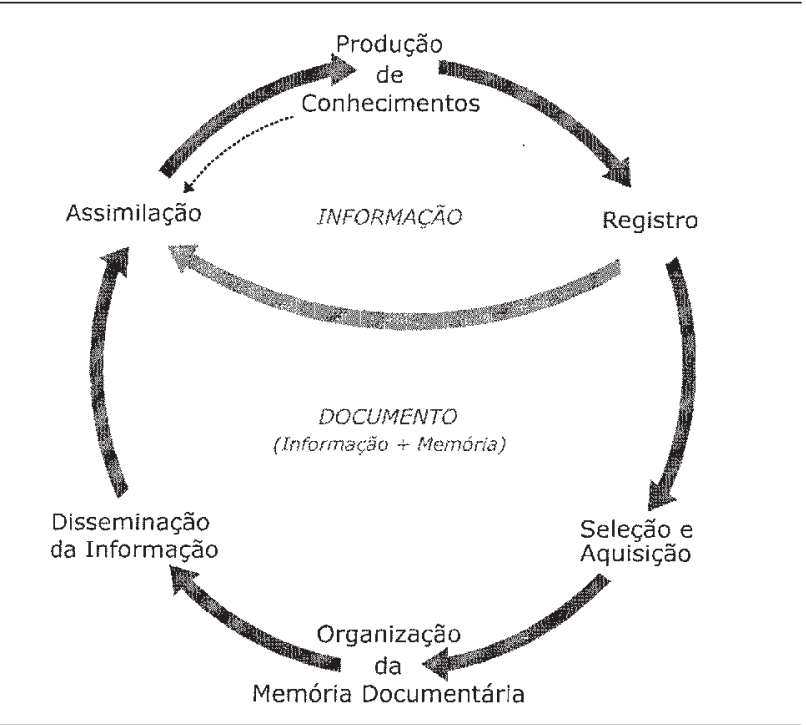

Fonte: extraído de Dobedei, 2002, 120 p.

Ci. Inf., Brasília, v. 33, n. 2, p. 161-171, maio/ago. 2004 
Percebe-se, assim, a preocupação de todas as áreas com a produção constante de conhecimento e sua organização, em um ciclo produtivo contínuo, assim como a necessidade constante da adequação dessa organização com as tecnologias de ponta, onde o organizar, recuperar e divulgar passa a ser a função principal, onde se encontra o uso de linguagens documentárias, com destaque aos sistemas de classificação e tesauros, como se pode observar na home page do projeto de Desenvolvimento de Terminologia e Codificação de Materiais e Serviços da Construção (CDCON), no endereço http://www.ufjf.br, onde é apontada a importância do sistema de classificação e do tesauro na organização e sistematização da informação, na área de engenharia civil.

Percebeu-se, em toda a investigação, que os sistemas de classificação e os tesauros estão sendo os mais utilizados, tanto em nível nacional quanto internacional, para a organização do conhecimento, em todas as áreas, principalmente com os avanços constantes da tecnologia da informação e comunicação, conforme colocam Souza e Alvarenga (2004) sobre a importância da Web e das demais redes digitais de troca de informações no panorama mundial, que podem ser amostras de como a atividade de organização da informação é necessária para a evolução dos indivíduos, organizações e da sociedade em geral. Portanto, necessário o estudo sobre essas ferramentas, conforme apresenta-se a seguir um levantamento referencial sobre ambos.

\section{SISTEMAS DE CLASSIFICAC̣ÃO E TESAUROS}

Segundo a literatura, tanto os sistemas de classificação quanto os tesauros são utilizados na organização/ representação do conhecimento. Assim, apresenta-se a seguir um levantamento no qual se procura traçar um paralelo entre ambos, procurando destacar a importância de cada um no processo de organização do conhecimento na área da construção.

\section{Sistemas de Classificação: definições e princípios teóricos}

Classificação significa a ação e efeito de classificar, e classificar significa ordenar e dispor em classes. Uma classe consiste de um número de elementos quaisquer (objetos e idéias) que possuem alguma característica comum pela qual devem ser diferenciados de outros elementos e, ao mesmo tempo, constitui sua própria unidade. A determinação e a seleção das classes que compreendem um esquema de classificação estão essencialmente relacionadas com as necessidades de utilização de cada esquema.
A escolha de uma ou outra característica, em cada área específica, terá como resultado diferentes arranjos das realidades a classificar e, conseqüentemente, a constituição de diferentes classificações. Classificar é, então, escolher uma entre outras classificações logicamente possíveis, procurando encontrar, para a escolha feita, um conjunto de razões suficientes. Assim, o resultado de uma classificação é uma rede ou estrutura de relacionamentos aplicáveis a qualquer área do conhecimento (Lopes, 2002; Pombo, 2003).

Portanto, a classificação é um processo mental por meio do qual podemos distinguir coisas, seres ou pensamentos pelas suas semelhanças ou diferenças, estabelecer as suas relações e agrupá-las em classes de acordo com essas relações. A classificação torna-se, pois, a arte de colocar diversas coisas desordenadas em um todo ordenado (Souza, 1943 apud Straioto, 2001).

A classificação sumaria e ordena o conhecimento existente. Mas, para classificar, é necessária a existência de teorias tão mais profundas quanto mais detalhada se pretenda a classificação, que representem o conhecimento das propriedades e características dos objetos que se pretende classificar. Para além do conhecimento factual dos objetos, é necessário definir com rigor o propósito da classificação, de modo que se possa, por abstração, eliminar as propriedades que não são relevantes para a classificação e enumerar aquelas que permitem a distinção entre objetos. Classificar é associar objetos idênticos e separar objetos diferentes.

Resume-se, então, que a classificação é um conjunto de conceitos organizados sistematicamente de acordo com os critérios ou características escolhidas, conforme é apresentado a seguir, extraído da norma ISO TR 14177/ 94 - Classificação da informação na indústria da construção:

a) classes de classificação: unidade de alto nível dentro de uma classificação expressando um conceito principal;

b) definição de classe: formulação das características essenciais de uma classe de classificação que desenha uma clara fronteira entre ela e outras classes de classificação;

c) tabela de classificação: apresentação estruturada de itens de classificação de uma classe de classificação;

d) item de classificação: único conceito definido, unicamente dentro de uma classe de classificação; 
e) termo de classificação: designação de uma classe de classificação ou item de classificação por meio de uma expressão lingüística;

f) notação: um identificador alfanumérico. Trata-se de um sistema de códigos expressando o arranjo de uma classificação.

Geralmente, os sistemas de classificação da informação consistem de três partes: um esquema de classificação que organiza nomes sistematicamente de acordo com suas similaridades; uma notação da classificação que substitui itens no esquema de classificação; um índice para tornar fácil para o usuário pesquisar a informação. O esquema de classificação final deve ter a função de representar o campo que é classificado.

Considerando que um dos pontos fundamentais dos sistemas de classificação é sua divisão em classes, discutese a seguir essa divisão, na qual a classe é dividida em subclasses, e assim sucessivamente, em unidades subseqüentes a primeira e associadas a um conjunto cada vez mais particular da propriedade da classe anterior. As subclasses criadas de acordo com esse conceito denominam-se por classes subordinadas. Também é possível associar classes de nível superior, que representem a inserção do conjunto de propriedades que caracterizam essa classe em um conjunto mais generalista. As classes criadas dessa forma designam-se por subordinantes. As classes no mesmo nível de divisão designam-se por classes coordenadas. Uma classificação hierárquica é aquela que apresenta uma estrutura de classes subordinantes - coordenadas - subordinadas. Dessa forma, a divisão das classes baseia-se no:

a) princípios de divisão: as classes são divididas em subclasses, de acordo com um aspecto particular (critério escolhido) que corresponde ao princípio de divisão, isto é, a divisão faz-se atendendo a uma característica particular da classe. Nas abordagens de modelização da realidade, esse tipo de abordagem é denominado por especialização. Em modelização, também se usa o conceito de decomposição, que pressupõe a divisão de uma classe, de acordo com os componentes dela, e não com as características ou atributos dos seus componentes, como no caso da especialização (Monteiro, 1998);

b) classes simples e classes compostas: uma classe simples representa unicamente um princípio de divisão ou uma característica única em que não ocorrem subdivisões mais específicas. Já em uma classe composta, reflete-se mais que um princípio de divisão, e pode ocorrer o desdobramento do princípio em termos correlatos no âmbito de uma classe convencional.
Assim sendo, os sistemas de classificação vão sendo construídos em qualquer área, e é necessária a identificação de todos os elementos e processos que a envolvem e sua estruturação e adequação a um sistema de classificação específico. Assim, encontram-se vários tipos de sistemas, como se define a seguir.

\section{Tipos de Classificação}

\section{Classificações Especializadas e Gerais}

Uma classificação denomina-se por especializada, se tiver por objetivo um assunto em particular, como, por exemplo, o sistema de classificação da United Classification for the Construction Industry (Uniclass), direcionado à indústria da construção, ou geral, se pretende cobrir o universo mais complexo da informação, como, por exemplo, à área de ciência da informação, a Classificação Decimal Universal (CDU).

\section{Classificações Analíticas e Documentais}

Uma classificação denomina-se analítica quando pretende sistematizar fenômenos físicos e providencia uma base para a sua explicação e entendimento. Também se denominam por classificações científicas ou taxonomias, como exemplo, a classificação do reino animal. Uma classificação designa-se como documental, quando a sua utilização pressupõe a classificação de documentos ou outros tipos de informação, com o objetivo principal de facilitar a localização dessa informação, como exemplo, a Classificação Decimal Dewey (CDD), bastante utilizada em bibliotecas.

Classificações Enumerativas e Classificações por Facetas

\section{Classificações enumerativas (ou decimais)}

São classificações que prescrevem um universo de conhecimento subdividido em classes sucessivamente menores que incluem todas as possíveis classes compostas (relações sintáticas). Essas classes são organizadas de forma a apresentar suas relações hierárquicas. Apresentase em listagem exaustiva de termos, organizados em classes e subclasses. Este tipo de classificação é limitativo, uma vez que coloca dificuldades à inserção de novos termos. A ordem predefinida para os termos em cada classe apenas permite a introdução de novos termos de forma seqüencial. Relativamente à notação, por exemplo, de produtos, os dígitos de reserva necessários para a introdução de novos produtos são de difícil previsão, podendo tornar a notação muito extensa (Monteiro, 1998).

Ci. Inf., Brasília, v. 33, n. 2, p. 161-171, maio/ago. 2004 


\section{Classificações por facetas}

Desenvolvida por Shiyali Ramamrita Ranganathan na década de 1930, atualmente tem sido largamente discutida na academia como uma solução para a organização do conhecimento, em decorrência de suas potencialidades de acompanhar as mudanças e a evolução do conhecimento. Muitos termos e expressões têm surgido, mas retratam nada mais do que a classificação facetada que, segundo Ranganathan (1967) apud Campos (2001), conceitua o conhecimento "coma totalidade das idéias conservadas pelo ser humano" por meio da observação das coisas, fatos e processos do mundo que o cerca.

A expressão análise em facetas foi adotada por Ranganathan para indicar a técnica de fragmentar um assunto complexo* em seus mais diversos aspectos/partes constituintes, que são as facetas, utilizando, para estabelecer a relação entre eles as "categorias fundamentais", de noções abstratas, denominadas Personalidade, Matéria, Energia, Espaço, Tempo, conhecidas pela PMEST. Personalidade é a característica distinguindo o assunto; Matéria é o material físico do qual um assunto pode ser composto; Energia é uma ação que ocorre com respeito ao assunto; Espaço é o componente geográfico da localização de um assunto; Tempo é o período associado com um assunto (Prescott, 2003).

Assim, a classificação facetada é conhecida como um esquema analítico sintético porque envolve dois processos distintos: a análise do assunto em facetas e a síntese dos elementos que constituem o mesmo, sendo, portanto, aplicável a qualquer área do conhecimento. Analisa-se o assunto fragmentando-o em suas partes constituintes, decompondo elementos mais complexos (assuntos) em conceitos simples (conceitos básicos ou facetas), e é sintético na medida em que procura sintetizar, condensar, examinar cada uma dessas partes, para, posteriormente, uni-las de acordo com as características do documento que vai ser descrito e representado. $\mathrm{O}$ núcleo central da análise facetada é a distribuição dos termos relacionados com determinado domínio do conhecimento em facetas homogêneas que se excluem mutuamente e que derivam de uma fonte comum pela aplicação rigorosa de uma só característica de divisão. Nos sistemas facetados, a divisão é realizada em cadeia, ou seja, determinado assunto vai sendo dividido em

\footnotetext{
* Assuntos complexos são os que refletem duas ou mais facetas de classes básicas diversas. Exemplo: influência da política econômica na construção de casas populares.
}

subclasses até esgotarem-se as possíveis variações (Campos, 1975; Maple, 1995).

Desse modo, o termo categoria fundamental é usado por Ranganathan para representar idéias fundamentais que permitem recortar um "Universo de Assunto" (um "corpo" ou uma parte de determinado conhecimento a ser organizado e sistematizado) em classes bastante abrangentes. As categorias fundamentais, segundo Campos (1998), funcionam como o primeiro corte classificatório. Por sua vez, são elas que fornecem a visão de conjunto dos agrupamentos que ocorrem na estrutura, possibilitando assim o entendimento global da área. Os seja, uma categoria é um conjunto de propriedades de qualidades semelhantes que, na visão do usuário, satisfaz uma mesma necessidade. O uso de categorias na organização de conceitos e, em conseqüência, na elaboração de uma classificação é um recurso para o entendimento da natureza do conceito e para a formação das estruturas conceituais. As categorias possibilitam a sistematização do conhecimento.

Há controvérsia sobre o significado de categorias, facetas e classes. Segundo Ferreira (1994), categoria é um conceito de alto grau de generalidade que define, em perspectivas e níveis diversos, o domínio do conhecimento e da ação. Já para Vickery (1980) apud Straioto (2001), categorias são conceitos de alta generalidade e ampla aplicação empregados na interpretação do mundo. Piedade (1983) define categorias como sendo as grandes classes, os grandes tipos de fenômenos presentes no conhecimento em geral ou em uma de suas partes.

Tem-se Langridge (1977) apud Straioto (2001) que apresenta algumas considerações que podem ser significativas ao se tentar estabelecer a diferença entre categorias e facetas. Para ele, as categorias são aplicáveis no todo, ou em grande parte do conhecimento, e são conhecidas como "categorias fundamentais". No contexto de uma determinada classe, usa-se o termo faceta. Concluindo-se, usa-se o termo "categorias", quando nos referimos à estrutura geral de um esquema de classificação, e "facetas", quando nos referimos à manifestação dessas categorias em classes diferentes.

A classificação facetada contém ambas as categorias fundamentais - assuntos básicos e suas facetas -, e estas, por sua vez, contêm "isolados”, que são os diversos assuntos, em âmbito mais específico, dentro de qualquer faceta. Um assunto básico pode estar sozinho, por exemplo, "literatura", dentro de uma faceta no assunto "literatura inglesa". Um isolado, ao contrário, é um termo 
que media um assunto básico, tal como o termo "inglês". Para criar um número de classe, o assunto básico é nomeado primeiro. Os isolados seguem, entrando de acordo com a fórmula da faceta. Essa fórmula declara que cada isolado em cada faceta é uma manifestação de uma das cinco categorias fundamentais: Personalidade, Matéria, Energia, Espaço e Tempo.

Assim, cada termo dentro de uma faceta é chamado de "isolado". Os isolados, as subclasses, isto é, cada termo em si, embora mantendo as mesmas amplas relações com a classe que lhes deu origem, estão todos misturados, apresentando características diferentes. Para que possam receber notações, é preciso que sejam arrumados dentro das facetas. Aplica-se mais um principio de divisão subfacetas. Segundo Barbosa (1972, p.75), subfacetas são grupos de termos coordenados, derivados pela aplicação de um mesmo princípio de divisão e mutuamente exclusivos. Se aplicarmos mais uma diferença na classe, temos as subclasses. Se na subclasse aplicar outra diferença, a subclasse passará a ser a classe, mais uma divisão se tornará subclasses, até o máximo de subdivisões que o assunto comportar.

Ocorre muitas vezes o fato de, ao classificar um assunto, percebe-se a necessidade de que uma mesma categoria seja utilizada mais de uma vez, isto é, algumas categorias podem aparecer novamente, ao se classificar determinado assunto. Surgiriam, então, os denominados ciclos ou rounds.

As propriedades que determinam as classes em uma determinada área do conhecimento podem ser ordenadas por uma crescente especificação do geral para o particular. Propriedades de um patamar (renque) superior são gerais e propriedades de patamares inferiores são específicas (Ekhlmon, 1996).

Nas classificações por facetas, criam-se subclasses a partir de um princípio simples e particular de divisão da classe principal e definem-se classes compostas por associação destas. Portanto, é necessário definir a ordem pela qual as facetas são agrupadas, normalmente uma das características que se considera mais relevante, em absoluto ou relacionada com a abordagem que se pretende na realidade. A essa definição chama-se ordem de citação.

Ordenamento sistemático em uma classificação facetada consiste em dispor as facetas em ordem de citação, de acordo com sua relevância aos usuários da classificação. Termos nas facetas são ordenados por seu interrelacionamento (proximidade conceitual).

Ranganathan, ao lançar seu sistema, utilizou o sinal de dois pontos para introduzir qualquer uma das facetas.
Esse sistema significou a possibilidade de inter-relação de conceitos, rompendo com a tradição demasiadamente hierárquica. Além disso, tornaria possível que se acompanhasse a evolução do conhecimento. Como ressalta Barbosa (1972), essa nova técnica permite maior flexibilidade aos sistemas, por não prendê-los a uma hierarquia de divisão, e veio resolver o problema da classificação de assuntos de conceitos multidimensionais e dar novos rumos aos estudos teóricos das classificações bibliográficas.

Dessa maneira, percebe-se que a classificação facetada é a mais recomendada para ordenar assuntos multidisciplinares e mais detalhistas como a área da construção. Nela pode-se trabalhar as classes principais ou categorias fundamentais, as subclasses, as facetas e os termos isolados. Destacam-se, a seguir, algumas diferenças entre os sistemas de classificação tradicionais e sistemas facetados.

Diferenças entre sistemas de classificação tradicionais e sistemas facetados

Prieto-Díaz (1987) explica que ambos os esquemas podem representar o mesmo número de classes. Contudo, no esquema hierárquico, classes com mais de um componente elementar são imediatamente incluídas na classificação, enquanto, para o esquema facetado, temse de sintetizar elementos de múltiplas classes.

Em contrapartida, Kant (1974)* apud Campos (1978) adverte que a lógica aristotélica constituiu até pouco tempo a espinha dorsal dos sistemas de classificação bibliográfica. Os sistemas cingiram-se, quase sempre, a um tipo de relacionamento entre conceitos. E, como a relação mais acentuada na lógica aristotélica é a de inclusão (gênero-espécie), foi sobre esse único tipo de relacionamento que foram elaborados os sistemas tradicionais de classificação bibliográfica. A conseqüência foi à emergência de sistemas rigorosamente enumerativos.

Portanto, os esquemas de classificação tradicionais são construídos na base de estrutura em árvore, com ênfase nas subdivisões para baixo, dentro de classes mais específicas e menores. Freqüentemente, as relações que são conhecidas são aquelas de super e subordinação e não fornecem relações sintáticas. Como resultado, a classificação usualmente é relativamente ampla e pode ser limitada para combinação entre classes, ou para expressar conteúdos semânticos complexos. Isso causa dificuldades quando se pesquisa em ambientes

* KANT, Immanuel. Crítica da razão pura. Trad. de Valério Rohden. São Paulo, Abril Cultural, 1974, p. 9. 
multidisciplinares, ou quando se lida com objetos de natureza complexa.

Já na classificação facetada a lógica interna do sistema é baseada em uma análise rigorosa do vocabulário, e termos são classificados dentro de um conjunto-padrão de categorias funcionais. Dentro dessas categorias, várias relações semântica são conhecidas e problemas de controle de vocabulário são endereçados. Um sistema sofisticado de sintaxe provê a ordem e a combinação dos termos intra e entre facetas (Broughton, 2002).

Segundo Prieto-Díaz (1987), os esquemas facetados são mais flexíveis, mais precisos e mais adequados à classificação de coleções de muitos elementos e com crescimento permanente. Em biblioteconomia, esquemas facetados são construídos a partir da escolha de uma amostra da coleção a ser classificada, um processo denominado "garantia literária". Termos são escolhidos dos textos selecionados, agrupados, e, então, as facetas são definidas a partir dos grupos. As facetas são então classificadas em ordem de citação, e os termos, em cada faceta, ordenados arbitrariamente, de acordo com as necessidades dos usuários. Por exemplo, os termos na faceta "planetas do sistema solar" (nome dos planetas) podem ser ordenados por seu tamanho, distância do Sol ou em ordem alfabética, dependendo do que for mais relevante ao usuário. Assim, em um esquema de classificação facetada, as facetas podem ser consideradas dimensões em um espaço de classificação cartesiano, e o valor de uma faceta é a posição do artefato naquela dimensão (Pietro-Diaz, 2001).

\section{TESAURO E A RELAC̣̃̃O COM SISTEMA DE CLASSIFICAC̣ÃO FAĆETADA E TEORIA DO CONCEITO}

Grolier* (1976) apud Campos (1978) descreveu que os tesauros são as classificações que não ousam dizer o próprio nome [...] e que a proliferação dos mesmos é sintoma do crescimento desordenado e anárquico de classificações dissimuladas. Em contrapartida, Motta (1987) diz que tesauro é um vocabulário de termos relacionados genérica e semanticamente sobre determinada área de conhecimento. E é isso que se encontra na literatura e em várias áreas do conhecimento em que são desenvolvidos tesauros e/ou vocabulários de termos, que nada mais é do que uma seleção de termos, baseados em análise de conceitos, na qual se define o

\footnotetext{
* GROLIER, Eric de. La classification cent ans après. Bulletin de l' Unesco à l' Intention des Bibliothèques 30 6):349-358,nov./déc. 1976.
}

termo geral, de maior abrangência, e sua relação com termos mais específicos, que representam os conceitos menores.

O esquema de classificação facetada é atualmente um caso especial do que são os chamados vocabulários controlados ou tesauros, tanto que Dahlberg (1978) propõe que os tesauros podem ser distribuídos da seguinte maneira:

a) os que dizem respeito a objetos, como minerais, plantas, animais etc. ... (fala-se de taxonomia);

b) os que dizem respeito a uma disciplina, aqui se podem falar de classificações mono ou pluridisciplinares;

c) os que dizem respeito a todas as disciplinas ou assuntos, que são as chamadas classificações universais.

Campos (1994), em uma pesquisa na área de representação e recuperação da informação, mostrou a existência de princípios comuns entre aspectos teóricos de instrumentos como os sistemas de classificação e tesauros, que têm por base a Teoria da Classificação Facetada, a Teoria do Conceito e a Teoria Geral da Terminologia, para a formação de estruturas sistemáticas, pois os conceitos de uma área de conhecimento se encontram relacionados entre si. Esses princípios são constituídos por elementos que estão na base da formação de tal estrutura, que são os conceitos, as relações entre os conceitos e a própria apresentação do sistema de conceitos.

O desenvolvimento das classificações facetadas e as pesquisas sobre tesauros trouxeram a convicção de que se deveriam considerar como elementos básicos na construção dos sistemas de classificação não as classes (como subdivisões de um todo), mas os conceitos na sua fecunda capacidade de expressão e de combinação. Mudou também o sentido de sistemas de classificação, que, em vez da apresentação sistemática de classes, pensase nos conceitos orientados para o objeto, conforme se apresenta na Teoria do Conceito, desenvolvida por Dahlberg (1993, p. 225) apud Campos (1995).

A Teoria do Conceito apresenta princípios que podem auxiliar na determinação do conceito e de suas relações, seja para elaborar tabelas de classificação, seja para elaborar tesauros. Ou seja, é um método para fixação do conteúdo do conceito e para seu posicionamento em um sistema de conceitos. O conceito não é apenas um elemento de significação do termo: o termo acaba sendo um elemento do próprio conceito - o terminum - que sintetiza o conceito como um todo e permite a 
comunicação, nesse caso, verbal. Não importa se o termo é formado por uma ou mais palavras, se é constituído por um substantivo mais um adjetivo etc. $\mathrm{O}$ que importa é que ele denota um referente. Assim, tratar o termo como representante de um referente, com suas características, é dar a ele um tratamento terminológico. E o estabelecimento de uma equivalência entre o termo (o definiendum) e as características necessárias de um referente de um conceito (o definiens), com o propósito de delimitar o uso do termo em um discurso, resulta na definição desse conceito dentro de um sistema. A definição não é mais só um recurso para dirimir dúvidas no uso do termo. A definição possibilita, além da fixação do conceito, seu posicionamento no próprio sistema de conceitos (Dahlberg, 1978).

A definição do termo é importante, na medida em que ele fornece características do conceito que vão permitir seu agrupamento, a formação das categorias e indicar as relações. Características usadas na comparação entre conceitos conduzem a um sistema de classificação de conceitos. A definição melhor surge no final da etapa de estruturação, quando se sabe exatamente qual é o significado do termo e qual a abrangência útil do conceito. Um termo tem várias definições, escolhe-se a mais útil.

As características identificam, descrevem uma qualidade de um objeto individual. As características são usadas para definir os conceitos e auxiliar a formação de novos termos para novos conceitos. Por meio das características, reúnem-se vários conceitos em classes e subclasses, formando assim os sistemas de classificação e tesauros, direcionados a cada área do conhecimento. Para os termos pertencerem a uma classe, devem ter uma característica comum, como, por exemplo:

ABSTRACTS: publicação periódica e resumos de artigos

REVISTA CIENTÍFICA: publicação periódica que contém comunicações científicas

CARACTERÍSTICAS COMUNS: publicação e periodicidade que os aproxima em um sistema de conceitos. A análise do conceito mostra que se trata de uma publicação que por sua vez é um documento, assim chega-se à classe geral: Documento - Publicação Publicação periódica - Periódico de resumos.

Dahlberg (1978a) utiliza a noção de categoria sob dois aspectos: como um recurso para o entendimento da natureza do conceito e como para a formação de estruturas conceituais. A importância fundamental da categoria na estruturação do conceito e do sistema de conceitos é enfatizada pela mesma autora, quando afirma que se pode ver que as categorias têm uma capacidade de estrutura: não apenas estruturam todos os elementos de conhecimento e unidades de conhecimento; elas fornecem, ao mesmo tempo, por esse meio o esqueleto, os ossos e os tendões para estruturar todo o conhecimento. Com o uso consciencioso, então, o corpo do conhecimento pode se manter unido, pode, se mover, pode se manter flexível e pode crescer organicamente.

Já na terminologia, estudam-se os conceitos enquanto parte de um sistema. Os termos se definem uns em relação aos outros, formando um sistema. Estenda-se aqui terminologia, conforme definida por Irazazábal* (1988) apud Curras (1995), como uma elaboração de um sistema de conceitos, reflexo da sistematização realizada em um campo do conhecimento, com fins de entendimento entre os especialistas. Um desses fins se concretiza nos processos classificatórios desse campo de conhecimento, para seu melhor uso e aproveitamento.

A terminologia se ocupa, sempre, de uma área de conhecimento em que há uma seleção das características relevantes para aquela área e, também, para os propósitos do trabalho. Assim, conforme a área e conforme o ponto de vista abordado, mudam as características e conseqüentemente as relações entre os conceitos, e é por esse motivo que os tesauros são desenvolvidos de forma específica a cada área do conhecimento. Ao selecionar as características a serem usadas para definir um conceito, é importante considerar a natureza do sistema de conceitos a ser construído, bem como as expectativas dos usuários. Extensão e intensão são as formas de apreensão e identificação do conceito e influenciam a elaboração de sua definição. A extensão é o número de conceitos que um conceito abarca, e intensão é o agregado de características de um conceito e está relacionada com a delimitação das características (Campos, 1998). Portanto, intensão é o conjunto de características de um conceito. Quanto mais características possuir um conceito, maior sua intensão, mais específico ele se torna. Por exemplo: miocardite chagásica é mais especifico do que doença de chagas, e a hierarquia seria: Doença - Doença parasitária - Doença de Chagas - Miocardite chagásica.

* IRAZAZABAL, A. " La terminología. ¿Por qué?; en Noticias de la SEDIC, Madrid, 1988, 7-16. Trabajo mecanografiado. 
Assim, a Teoria do Conceito é largamente utilizada no desenvolvimento de sistemas para a organização do conhecimento, exigindo relacionamentos entre os termos, conforme se apresenta a seguir.

\section{Relacionamento entre conceitos: elaboração da estrutura do sistema de classificação}

Os conceitos se relacionam uns com outros formando um sistema de conceitos terminológico, pois são as representações mentais das relações que ocorrem entre objetos na realidade empírica. Quando tratadas em um nível conceitual, passam a ser consideradas relações lógicas e ontológicas. As relações lógicas resultam da própria compreensão dos conceitos. Chama-se também de relação de semelhança, de similaridade, de abstração ou genérica. As relações ontológicas se dão entre o conceito e a realidade. A identificação das relações entre conceitos permite, em primeiro lugar, o entendimento do próprio conceito, tendo em vista que os conceitos se definem uns em relação aos outros. Além disso, elas auxiliam na formação das estruturas conceituais, em especial, aquelas que formam renques e cadeias (Campos, 2001).

Ranganathan (1967)* apud Campos (2001) propõe uma série de conceitos que estruturam a construção da classificação facetada:

a) assunto básico representam as áreas abrangentes do conhecimento;

b) idéia isolada, juntamente com o assunto básico, forma um componente específico de assunto;

c) características detêm as propriedades, qualidades ou quantificação de uma propriedade;

d) cadeias, série vertical de conceitos em que cada conceito tem uma característica a mais ou a menos conforme a idéia seja descendente ou ascendente;

e) renques são classes formadas a partir de uma única característica, formando séries horizontais;

f) facetas são manifestações de categorias do universo de conhecimento estudado.

Existem regras para se estabelecer uma conduta uniforme na formação dos renques e cadeias, como os da exaustividade e exclusividade. Exaustividade estabelece que as classes formadas por um renque devem ser

* RANGANATHAN, S R. (1967). Phelogema library classification. Bombay, Ásia Publishing House, 1967, 540 p. exaustivas, de modo que, se algum tópico novo surgir, ele deve ser acrescentado à estrutura, e esta deve ter hospitalidade para agrupá-lo em uma classe existente ou em uma classe recém-formada. Exclusividade estabelece que os elementos formadores dos renques devem ser mutuamente exclusivos, ou seja, nenhum componente da estrutura (isolado ou assunto básico) pode pertencer a mais de uma classe no renque.

Ranganathan elaborou uma série de princípios que visam a permitir que esses conceitos possam ser estruturados de forma sistêmica, isto é, os conceitos se organizam em renques e cadeias, essas estruturadas em classes abrangentes, que são as facetas, e essas dentro de uma dada categoria fundamental. A reunião de todas as categorias forma um sistema de conceitos de uma dada área de assunto e cada conceito no interior da categoria é também uma manifestação dessa categoria (Campos, 2001).

Assim, procurou-se identificar os vários tipos de relacionamentos possíveis no uso de conceitos, conforme se apresenta a seguir.

Tipos de relacionamentos

Existem vários tipos de relacionamentos entre conceitos, podendo-se destacar: relacionamento lógico (genérico/ específico, analítico, de oposição), relacionamento ontológico (partitivo, de sucessão, material/produto) e relacionamento de efeito (causalidade, instrumental, descendência, genealógica, estágios da substância, antogênica), detalhados a seguir (Gomes, 1996).

\section{Relacionamento lógico}

Quando existem características comuns nas definições dos conceitos, implica que há relacionamento direto entre os conceitos. Subdivide-se em genérico/específico, analítico, de oposição, conforme se apresenta a seguir.

a) Relacionamento genérico/específico - Permite formar as classes dos conceitos. Os membros (termos) de uma classe são os conceitos que pertencem a um mesmo gênero. Por exemplo: solo ácido é um tipo de solo quando se comparam os conceitos, verifica-se que solo ácido tem todas as características de solo e mais uma que lhe é própria, específica, o fato de ser ácido. Por isso, sólido ácido é uma espécie de solo. Conceitos assim estruturados formam uma hierarquia (vertical), pois ligam termos superordenados a termos subordinados. As relações de subordinação lógica é a de gênero-espécie. A coordenação lógica ocorre quando os dois conceitos analisados são específicos do mesmo termo genérico, ou seja, dá-se entre conceitos de um mesmo renque lógico. 


\section{Ana Maria Delazari Tristão / Gleisy Regina Bóries Fachin / Orestes Estevam Alarcon}

b) Relacionamento analítico - Relacionamento não só hierárquico. Por exemplo dá-se: arquivamento está presente em arquivos correntes/intermediários/permanentes. Arquivamento é a característica que os une, então o termo arquivamento está associado a arquivo corrente, intermediário e permanente. Está relacionando, mas não é um tipo de, ou espécie. A relação se dá segundo o processo (arquivamento), e não o gênero/espécie. É necessário analisar o conteúdo, suas características para estabelecer as relações.

c) Relacionamento de oposição ou quase sinônimos Apresentam-se de três maneiras distintas: os relacionamentos de oposição contraditório (ausente/ presente; numérico/não numérico), os relacionamentos de oposição contrária (amizade/inimizade; amor/ódio) e o relacionamento positivo/indiferente/negativo (muito valioso/valioso/pouco valioso).

\section{Relacionamento ontológico}

As relações ontológicas são relações indiretas entre conceitos porque resultam das propriedades que possuem os representantes dos conceitos (os objetos do mundo empírico). Caracterizam-se pela contigüidade no tempo e no espaço ou pela conexão de causa e efeito. São classificadas em dois grupos distintos: relações de contato e relações de causalidade. Relações de contato são as relações partitivas, e as de causalidade são baseadas em um elo sucessivo de causas, como parentesco, materialproduto, instrumentos e seus usos. As relações ontológicas ocorrem quando um conceito é visto também como um objeto individual. Por exemplo: avião anfíbio - enquanto conceito ele é um tipo de avião, enquanto objeto individual terá partes apropriadas, como a aterrissagem e amerrisagem. Essas partes têm uma relação partitiva com avião anfíbio. Para o avião anfíbio pousar na terra e na água, ele precisa ter partes apropriadas, essas partes guardam com o conceito avião anfíbio uma relação partitiva: TEP - designa PARTE - e TGP - designa o TODO. Outro exemplo: FISICA TEP Física Nuclear; Física Nuclear TGP Física.

Relações partitivas são indiretas e se dão entre objeto, mas não são as únicas. Quando as relações se dão no tempo e espaço ou pela conexão causa/efeito, a relação é associativa. Então, na relação ontológica, o termo é visto como um objeto. Podem ser partitivas (TEP, TGP) e de Associação (TA). Nesse caso, a associação indicando material - produto, desde a matéria-prima ao produto final. Por exemplo: Filme fotográfico (material) TA Fotografia (produto).
Relacionamento de efeito

Trata-se de associação indicando o efeito, como: a) causalidade (pista molhada = acidente); b) instrumentalidade (Tabela de temporalidade - TA = eliminação; broca de perfuração $-\mathrm{TA}=$ Broca) e c) descendência (relação genealógica, ontogênica e estágios de substância). Como exemplos, Urânio I TA Urânio II.

Características não equivalentes são usadas na formação de sistemas de conceitos diferentes. Exemplo: edifício por função: igreja, teatro, escola; por estrutura - infraestrutura, estrutura, supra-estrutura.

A vantagem de se trabalhar com conceito e, portanto, com definições é a segurança no estabelecimento das relações. Exemplo: janela é conceituada como um vão; e janela basculante como uma estrutura que veda o vão. Portanto, janela basculante não é um tipo de janela. Portanto, a relação que se estabelece entre estes dois termos é associativa.

\section{CONSIDERAÇÕES FINAIS}

Percebe-se, de acordo com os levantamentos efetuados, que a classificação facetada e o tesauro são mecanismos utilizados de forma bastante intensa e, atualmente os mais estudados como recurso para a organização do conhecimento. Ambos, pelo fato de trabalhar o conceito, apresentam-se mais aptos a atender a demanda em todas as áreas do conhecimento.

Destaca-se que os tesauros são mecanismos que formam uma estrutura de conceitos, ou seja, criam uma lista de termos relacionados entre si, definindo os termos mais usados, quer de forma geral, quer de forma mais específica e suas co-relações.

Já os sistemas de classificação, além de criar termos gerais e específicos, distribuem-nos em classes ou categorias gerais e específicas, usando facetas ou subclasses, criandose um sistema co-relacionado e indica o uso de signos, ou seja, onde determinado assunto, ou material, ou produtos, ou serviço é substituído por um código (notação) e assim organizado e facilmente recuperado.

Portanto, enquanto os tesauros têm dois planos de trabalho - o plano das idéias e o plano verbal, ordenando os conceitos e permitindo uma recuperação eficaz -, o sistema de classificação abrange três planos de trabalho - o plano das idéias, o plano verbal e o plano notacional, pelo qual os documentos são armazenados e também recuperados de forma eficaz. 
Sistema de classificação facetada e tesauros: instrumentos para organização do conhecimento

Assim, o tesauro e o sistema de classificação apresentam diferentes níveis e profundidade de organização e podem co-existir em um sistema de recuperação de informação, complementando um as deficiências do outro.

Percebe-se que o aprofundamento teórico conceitual sobre os princípios que fundamentam a concepção dos sistemas de classificação facetada é um tema bastante atual, tendo em vista que a Web e tantas outras redes digitais que abrangem o mundo como um todo necessitam de uma troca de informações eficazes, rápidas e objetivas.

A questão da adoção de padrões internacionais no desenvolvimento, construção e disponibilização de informações na Web também tem sido uma preocupação constante aos estudiosos da área, em parceria com especialistas de áreas específicas, como o caso da área da construção civil.

Deste modo, estuda-se o sistema de classificação facetada como recurso para a organização das informações da área da construção civil. Constatou-se que o sistema de classificação facetada e o tesauro são passíveis de aplicação nessa área e impulsionam a continuidade dos estudos e pesquisas, pois a tecnologia avança a passos largos e fazse necessária a adequação específica de cada área do conhecimento, para permitir a socialização das informações em todos os níveis das organizações e da sociedade como um todo.

\section{Artigo recebido em 08-06-2004 e aceito para publicação de 18 a $21 / 10 / 2004$}

\section{REFERENCIAS}

BARBOSA, Alice Príncipe. Classificações facetadas. Ciência da Informação, Rio de Janeiro, v. 1, n. 2, p. 73-81, 1972.

BROUGHTON, Vanda. Facet analytical theory as a basis for a knowledge organization tool in a subject portal. Disponivel em: < http://www.ucl.ac.uk/ fatks/paper2.htm>. Acesso em: 20 out. 2003.

CAMPOS, Astério. O processo classificatório como fundamento das linguagens de indexação. Revista de Biblioteconomia de Brasília, Brasília, v. 6, n. 1, p. 1-8, jan./jul. 1978.

CAMPOS, Maria Luiza de Almeida. Em busca de princípios comuns na área de representação da informação: uma comparação entre o método de classificação facetada, o método de tesauro-baseado-em-conceito e a teoria geral da terminologia. 1994. 196 f. Dissertação (Mestrado em Ciência da Informação) - Instituto Brasileiro de Informação em Ciência e Tecnologia, Universidade Federal do Rio de Janeiro, Rio de Janeiro, 1994.

. A organização de unidades do conhecimento em hiperdocumentos: o modelo conceitual como um espaço comunicacional para realização da autoria. 2001. Tese (Doutorado em Ciência da Informação) - Instituto Brasileiro de Informação em Ciência e Tecnonologia, Universidade Federal do Rio de Janeiro, Rio de Janeiro, 2001.
Perspectivas para o estudo da área de representação da informação. Ciência da Informação, Brasília, v. 25, n. 2, 1995. Disponivel em: < http://www.ibict.br/cionline/250296/25029611>. Acesso em: jan. 2002 .

- Princípios teóricos da organização do conhecimento e sua influência nas novas tecnologias de informação. In: SIMPÓSIO: ESTADO ATUAL E PERSPECTIVAS DA CDU. 1996. Brasília : IBICT, 1996, p. 74-77.

CDCON: desenvolvimento de terminologia e codificação de materiais e serviços para construção - relatório parcial. [S. 1. : s. n.], 2003. 56 p. Disponível em: Arquivo Beta. Atualizado em: 17 fev. 2003.

DAHLBERG, Ingetraut. Classification theory: yesterday and today. International Classification. v. 3, n. 2, p. 85-90, 1976.

. Fundamentos teórico-conceituais da classificação. Revista de Biblioteconomia de Brasilia. Brasília, v. 6, n. 1, p. 9-21, jan./jul. 1978b.

Teoria do conceito. Ciência da Informação, Rio de Janeiro, v. 7, n. 2, p. 101-107, 1978a.

DOBEDEI, Vera Lúcia Doyle. Tesauro: linguagem de representação da memória documentária. Niterói, RJ : Intertexto; Rio de Janeiro : Interciência, 2002. 120 p.

EKHOLM, A.; FRIDQVIST, S. A conceptual framework for classification of construction works. Itcon, v. 1, p. 1, 1996. Disponivel em:<http://www.itcon.org>. Acesso em: maio 2002.

GOMES, Hagar Espanha. A organização do conhecimento diante das novas tecnologias da informação. In: SIMPÓSIO: ESTADO ATUAL E PERSPECTIVAS DA CDU. 1996. Brasília : IBICT, 1996, p. 54-57.

INTERNATIONAL ORGANIZATION FOR STANDARDIZATION. Classification of information in the construction industry. Geneva, 1994. 1 v. (ISO techical report, 14177).

MAPLE, Amanda. Faceted access: a review of the literature. Disponivel em: 〈http://theme.music.indiana.edu/tech s/mla/facacc.ver >. Acesso em: mar. 2003.

MONTEIRO, Miguel. Classificação da informação na indústria da construção. 1998. Dissertação (Mestrado) - FEUP, Porto, 1998.

MOTTA, Dilza Fonseca da. Método relacional como nova abordagem para construção de tesauros. Rio de janeiro : SENAI, 1987. 89 p. (Coleção Albano Franco, n. 12).

POMBO, Olga. Da classificação dos seres à classificação dos saberes. Disponível em: <http://www.educ.fc.ul.pt/hyper/resources/opomboclassificacao.pdf>. Acesso em: ago. 2003.

PRESCOTT, L. Ranganathan and facet analysis. Disponível em: <http:// www.mysticseaport.org/library/msitia/facets.html>. Acesso em: ago. 2003.

SOUZA, Renato Rocha; ALVARENGA, Lídia. A web semântica e suas contribuições para ciência da informação. Ciência da Informação, Brasília, v. 33, n. 1, p.132-141, jan./abr. 2004. Disponível em: <http:/ /www.ibict.br/cienciadainformacao/viewarticle.php?id=71>. Acesso em: set. 2004 .

STRAIOTO, Ana Claudia. A análise em facetas como dimensão teórica e prática na organização do conhecimento. 2001. 163 f. Dissertação (Mestrado) - Faculdade de Filosofia e Ciências, Universidade Estadual Paulista, Marília, SP, 2001. 